\title{
COVID-19 Vaccination Perspectives Among Young Parents with Foster Care Backgrounds
}

\author{
Elizabeth M. Aparicio' ${ }^{1}$. Svetlana Shpiegel ${ }^{2}$. Genevieve Martinez-García ${ }^{3} \cdot$ Marissa Ventola $^{2}$. \\ Michelle Jasczynski ${ }^{1} \cdot$ Amara Channell Doig $^{1} \cdot$ Sheila Van Wert ${ }^{4} \cdot$ Alexander Sanchez $^{4} \cdot$ Rhoda Smith $^{5}$
}

Accepted: 3 February 2022 / Published online: 3 March 2022

(c) The Author(s), under exclusive licence to Springer Science+Business Media, LLC, part of Springer Nature 2022

\begin{abstract}
The COVID-19 pandemic has brought unique stressors for youth in foster care and recent foster care alumni, particularly those who are also parenting young children. One way the pandemic can be mitigated is through vaccination of the general population. Yet, some young adults have been slow to choose to be vaccinated. As has been demonstrated, simple availability of the COVID-19 vaccine will not guarantee its uptake, especially among marginalized populations. In order to better understand the nuances of vaccination among youth in foster care and recent foster care alumni, we conducted in-depth, semi-structured focus groups and interviews with 23 parenting youth with foster care histories aged 18-26 years. Data regarding vaccine attitudes were analyzed using thematic analysis. Participating youth, who were majority Black, Indigenous, and people of color (BIPOC) and often lived in multigenerational households, had significant concerns about the COVID-19 vaccine. They expressed varying degrees of intention to get vaccinated. Young people, especially those who belong to marginalized populations, need opportunities to openly discuss their vaccination-related questions without judgment. Science communicators should consider these questions and address youths' concerns through diverse voices and channels to ensure youth have the information they need to make an informed decision regarding COVID-19 vaccination.
\end{abstract}

Keywords COVID-19 $\cdot$ Vaccination $\cdot$ Foster youth $\cdot$ Adolescent health

\section{Introduction}

The United States Centers for Disease Control and Prevention has recorded more than 42 million cases and 675

Elizabeth M. Aparicio

aparicio@umd.edu

1 School of Public Health, Department of Behavioral and Community Health, University of Maryland, 4200 Valley Dr, 20742 College Park, MD, USA

2 Department of Social Work and Child Advocacy, Montclair State University, Montclair, USA

3 Healthy Teen Network, Baltimore, USA

4 Community-based youth researcher, College Park, USA

5 Erikson Institute, Chicago, USA thousand deaths due to COVID-19 nationwide as of late September 2021 (CDC, 2021). Understanding community members' beliefs and attitudes towards mitigating the virus's spread, including attitudes towards vaccination, is critical to public health. Young adults are key to combating the spread of COVID-19, particularly as they may be asymptomatic carriers and unknowingly spread the virus (Abbasi, 2020; Boehmer et al., 2020). A recent meta-analysis regarding vaccination has found that norms, perceived behavioral control, and, most strongly, attitudes, predict vaccination intentions (Xiao \& Wong, 2020). Yet, few studies have been conducted to explore young adults' concerns regarding vaccination, including subgroups of young adults that may be at heightened risk because of social conditions. Young parents in foster care and those who have recently aged out of foster care are disproportionately likely to reside in group settings 
and experience homelessness, making them particularly vulnerable to contracting COVID-19 (Dworsky et al., 2013; Fowler et al., 2017; Perri et al., 2020). The present study thus aims to examine vaccination attitudes among young parents currently or formerly in foster care.

\section{Understanding Attitudes Towards Vaccination}

Historical and contemporary medical and social system mistreatment of communities of color contributes to concerns about vaccination (Bailey et al., 2021; NEJM - Race and Medicine, n.d.; Racism in Medicine | The BMJ, n.d.; Washington, n.d.). Racial and ethnic minority groups often exhibit high vaccine hesitancy rates due to institutional racism coupled with ineffective public health messaging (Khubchandani et al., 2021; Razai et al., 2021). Young people with foster care backgrounds are predominantly Black, Indigenous, and people of color (BIPOC) (Dettlaff \& Boyd, 2020), and their hesitancy toward COVID-19 vaccination may be exacerbated by mistrusting public systems due to negative experiences related to their child welfare involvement (Connolly et al., 2012). These youth may feel that public systems do not have their best interests in mind, and may be slow to trust official messaging channels.

Whereas vaccination is common in early childhood as part of the CDC immunization schedule, fewer routine vaccines are given in adolescence and young adulthood (Birth18 Years Immunization Schedule $\mid C D C, 2021)$. The vaccine to prevent Human Papillomavirus (HPV) is one example of a vaccine administered during adolescence or young adulthood, and where parents of minors have a significant role in vaccinating their children. Although the rates of HPV vaccination have increased over the last 10 years (McQuillan \& Unger, 2017), some parents still refuse or delay HPV vaccination over various concerns about the vaccine. Short and long-term vaccination safety and side effects, lack of awareness of the vaccine, mistrust in the development and testing process, and conflicting messages over the vaccine are some of many concerns parents cite when making a decision whether or not to vaccinate their children (Gilkey et al., 2017; Lacombe-Duncan et al., 2018). In many ways, public concern about HPV vaccination mirrors current concerns about COVID-19 vaccination, and young people's beliefs and attitudes in this regard should be investigated to inform appropriate intervention.

\section{Current Study}

Understanding community members' concerns regarding COVID-19 vaccination is critical to informing an attuned public health response. To this end, it is particularly important to understand the attitudes of persons who are at high risk for contracting COVID-19, such as youth facing social and economic disadvantage. Young parents with foster care backgrounds represent a highly disadvantaged population (Combs et al., 2018; Shpiegel \& Cascardi, 2018), and their attitudes towards COVID-19 vaccination may impact both their own and their children's likelihood of getting vaccinated. However, foster youth are often connected to social services, and social workers are well-positioned to hear their concerns regarding vaccination and provide accurate information to answer their questions. The purpose of the present study is to explore the attitudes towards COVID-19 vaccination among young parents who have been in foster care, to inform possible intervention strategies to encourage vaccination in this high risk population.

\section{Methods}

\section{Ethics Approval}

Study procedures were approved by the Institutional Review Board at Montclair State University prior to the study beginning.

\section{Consent to Participate and for Publication}

Our team recruited participants virtually through emailed flyers and social media posts to Twitter, Instagram, and Facebook. Interested youth sent a text message to indicate their interest, after which a member of our study team reached out to explain study procedures, answer any questions, and ascertain interest.Youth were then emailed the informed consent form, which we reviewed again at the time of the interview to ensure participants had the opportunity to ask any final questions before consenting to participation. As part of the informed consent process, youth provided their consent for their experiences to be shared via public presentations and publications.

\section{Study Sample}

Participating youth were currently in or recently aged out of foster care in the United States and were parenting one or more children. All youth were aged 18-26 years, and the majority $(60 \%)$ were Black, Indigenous, and Latinx. See 
Table 1 for additional demographic characteristics of the study sample.

\section{Data Collection and Analysis}

We collected in-depth qualitative data January-March 2021 through 10 virtual focus groups or individual interviews for those unavailable for a group. Twenty-three youth provided information regarding their attitudes towards the COVID19 vaccine. As part of a larger semi-structured interview protocol, participants described in detail their attitudes towards COVID-19 vaccination. All interviews were audiorecorded, naturalistic verbatim transcribed, and checked for accuracy prior to analysis. Our team employed a structured thematic analysis approach (Braun \& Clarke, 2006), with two data analysts per transcript and weekly peer debriefing. We immersed ourselves in each transcript through multiple readings, coded each transcript line by line, organized codes into a thematic structure, checked the structure against the data, and named the themes (Braun \& Clarke, 2006). Findings were then shared with participants for member checking (Creswell \& Poth, 2018).

Table 1 Participant demographics $(N=23)$

\begin{tabular}{lll}
\hline Characteristic & $\begin{array}{l}\mathrm{n}(\%) \text { or } \\
\text { mean }( \pm \mathrm{SD})\end{array}$ \\
\hline Age & $\begin{array}{l}22.13 \\
\pm 2.36)\end{array}$ \\
Race/Ethnicity & $\begin{array}{l}\text { Black or African } \\
\text { American }\end{array}$ & $8(34.78)$ \\
& Non-Hispanic White & $10(43.47)$ \\
& Hispanic or Latinx & $8(34.78)$ \\
& American Indian or & $2(8.70)$ \\
& Alaska Native & \\
& Do not know/prefer & $1(4.35)$ \\
& not to answer & \\
Sex & Male & $4(17.39)$ \\
& Female & $19(82.60)$ \\
Geographic Area & & $10(43.48)$ \\
& West & $4(17.39)$ \\
& East & $2(8.70)$ \\
Biological children are currently & & $7(30.43)$ \\
in their care & South & $22(95.65)$ \\
ical child & & $6(26.09)$ \\
Number of children in their care & & $1.95( \pm 1.26)$ \\
\hline
\end{tabular}

\section{Positionality}

Our research team included community-based and university-based partners, with two young parenting former foster youth, one community-based researcher, three graduate students, and three university professors in schools of public health and social work (one of whom is a former foster youth and teen parent). We are a diverse group with regard to gender, sexual orientation, and race, including Black, Latinx, and White team members. We practiced reflexivity throughout this study, including reflecting on our attitudes and plans for COVID-19 vaccination, which are varied, and on our personal experience with COVID-19. This process ensured we were authentically representing participants' perspectives without our beliefs having undue influence on the analyses.

\section{Results}

As noted above, data collection for this study was conducted in January-March 2021, soon after the emergency approval of first COVID-19 vaccines in the US. During this period, participants' attitudes towards COVID-19 vaccination varied considerably, from total opposition, to ambivalence, to planning on vaccination. The majority of participants $(n=15,65 \%)$ planned not to get vaccinated. Five participants were considering vaccination or were unsure whether or not they would get vaccinated $(n=5 ; 22 \%)$. Three participants were planning on vaccination $(n=3,13 \%)$. Thematic analysis revealed three themes important to understanding youths' perspectives on COVID-19 vaccination, including (1) concerns about vaccination, (2) conditions for becoming more comfortable with vaccination, and (3) reasons for planning to get vaccinated. These are presented with their subthemes in Table 2.

Table 2 Themes and subthemes

\begin{tabular}{|c|c|c|}
\hline $\begin{array}{l}\text { Theme 1: Concerns } \\
\text { About Vaccination }\end{array}$ & $\begin{array}{l}\text { Theme 2: Conditions For } \\
\text { Becoming More Comfort- } \\
\text { able with Vaccination }\end{array}$ & $\begin{array}{l}\text { Theme 3: Reasons } \\
\text { for Planning to } \\
\text { get Vaccinated }\end{array}$ \\
\hline 1a. Self-determination & $\begin{array}{l}\text { 2a. Effectiveness data } \\
\text { (including with new } \\
\text { strains) }\end{array}$ & $\begin{array}{l}\text { 3a. Trusted col- } \\
\text { leagues and peers } \\
\text { getting vaccinated }\end{array}$ \\
\hline $\begin{array}{l}\text { 1b. Mistrust in vaccine } \\
\text { efficacy and develop- } \\
\text { ment process }\end{array}$ & $\begin{array}{l}\text { 2b. Addressing } \\
\text { misinformation }\end{array}$ & $\begin{array}{l}\text { 3b. Protecting self } \\
\text { and family }\end{array}$ \\
\hline 1c. Availability & 2c. Mandatory vaccination & $\begin{array}{l}3 c . \text { Hope for } \\
\text { return to normalcy }\end{array}$ \\
\hline
\end{tabular}




\section{Theme One: Concerns About Vaccination}

Subtheme 1a: Self-determination. Some youth felt strongly that nothing could be said or done to make them feel comfortable taking the COVID-19 vaccine or, later, vaccinating their children. Youth expressed wanting others to have the option to get vaccinated, however, asserting that people need to make their own decision. As one youth stated, "Yeah, personally, I wouldn't get it, but I would like it to be available for people. So, like - that would be an option for mothers, their families that are in need, or like, I guess lower income, or I don't know" (Lily).

Several participants felt that, due to safety concerns and uncertainty about how their body would react to the vaccine, it was not in their best interest to get vaccinated. Many of these youth discussed the idea of building natural immunity to the virus. As Phamous stated: "If you can get over a common cold without having to take medicine, I feel like you can get over this, you know, but everybody's different. And that's just the reason why I wouldn't take [the vaccine]."

Subtheme 1b: Mistrust in vaccine efficacy and development process. Young parents expressed several specific concerns about COVID-19 vaccination, including the belief that more data is needed on effects (including side effects), the vaccine was developed too quickly, suspicions about where the virus originated, and that the "Trump vaccine" was developed under an untrustworthy presidential administration in 2020.

Youth shared a sense that early adopters of the vaccine are "guinea pigs" and that they had no interest in being in such a position. They expressed similar concerns about vaccinating their children against COVID-19, even once the vaccine was tested and approved for them. As Franny shared:

"I wouldn't do it for my kids either. I wouldn't know how it would affect them. So I just think that they should probably wait for it to be put out to the general public because I know they're giving it to likelike the people that are first responders and stuff like that, but even then, some of 'em are experiencing side effects that they've never felt before. So, to me, I feel like those are their guinea pigs, and I don't want me or my children to become their guinea pigs because of this vaccine. So I just think I just-I wouldn't do it, not until I know that it's safe" (Franny).

Participants explained that part of their hesitation to take the vaccine is related to the way the media has portrayed it. As John shared:

"I've heard a lot of negative things - not from people who have had-uh, gotten the vaccine but from the media and stuff-um, about how, um, early the vaccine has come, uh, and how it possibly could be more, uh, hurt than, um, than help" (John).

Sage further shared, "At the same time I don't trust everything in the - in the US. That's why I won't trust the vaccine. [Laughter] Um, if there's - the government's not that trustable to me. Like, they do things, uh, to their benefit that's not gonna benefit lower-income people."

Subtheme 1c: Availability. Some youth believed that there would be a shortage of doses, even if they felt comfortable taking the vaccine. As one participant explained, "The thing is, they don't even have enough [of the vaccine and] they're still testing it" (Latti). Other youth had concerns about the availability of appointments, as they had already experienced delays when trying to schedule their vaccination. As Aaliyah recalled: "And when it comes down to getting the vaccine, I feel like it's gonna start becoming harder. I don't know if you're gonna have to pay for it, your insurance is gonna have to cover it, or, um-I know that I went to call to make an appointment last week, and the first week was already booked."

\section{Theme Two: Conditions for Becoming More Comfortable with Vaccination}

Subtheme 2a: Effectiveness data. The youth who were open to considering vaccination in the future noted that their minds could be changed by having more information about vaccination outcomes. In particular, they preferred to wait to observe effects as people in the general community took the vaccine, including "a report of side effects that people have noticed a month after getting it. ... I feel like that would put my mind at ease" (John). Participants expressed concern about new strains of the COVID-19 virus and whether the vaccine would "protect you from that one." As more people are vaccinated, more information will become available on side effects. As Dan shared:

"I have a lot of friends that are in the nursing field, and a lot of them have gotten really sick off of it [the vaccine]. A lot of them work in the field and a lot of them don't want to get it, even though they're mandatory to get it, um then they've just seen the effects that have happened to people and I'm not for it" (Dan).

Latti, who had COVID-19, had questions about how the vaccine specifically would affect people like her:

"I'm kind of skeptical because it's like there's so much we don't know about it. I mean, I'm open to learning more about it, and I probably would even take it. But I wanna know things about it, like what happens. And since I had COVID, like she said,, you have to wait a little bit. How will my body react to it? Like do-are there things I should 
be looking out for? Same with COVID. Because persons with COVID apparently, we should be getting tested, and we could re-get the virus again. So, it's like there's still so much information that we don't even know about COVID, and then we're gonna get a vaccine that we kind of don't know much about" (Latti).

Subtheme 2b: Addressing misinformation. Participants expressed deep concern regarding misinformation, and shared many examples of misinformation that had been shared with them. As Latti shared:

There's so much misinformation that people don't really know [what to believe]. And, when we get information, everybody's saying different things. One of my friends that had the virus also said that if you had COVID, you have antibodies, so you can't get it again" (Latti).

As with many other participants, as Dan shared his beliefs about the vaccine, they were intertwined with inaccurate information regarding how the COVID-19 vaccine works and a desire to use only vaccines that "I know, I trust, and I believe." As Dan expressed:

"I know it's supposed to be the lesser strand of it and things like that and I don't want no strand of COVID-19 or anything in my body at all, because you just gotta think down the line when you get a vaccination what it can do to your body over the time and over the years, you know. It could affect anything in your body. So then, you should watch what you take for vaccination, or what you use, because your body can react to different things and you know-I'm not calling people test dummies when it comes to the COVID vaccination. I'm just not for it and for what's in it, so stick to the vaccinations, I know, I trust, and I believe" (Dan).

Subtheme 2c: Mandatory vaccination. Youth spoke about the possibility of vaccination being mandatory as a condition for taking it. As Aaliyah explained, "They said it's, uh, it's an option to do the vaccine, but it's not mandatory, I guess. So, that's a decision I have to come to, to do." Although the vaccine being mandatory would not in itself address youths' concerns, it would force them to consider their concerns and get them addressed. As Sage explained,"I will not get it. My kids will not get it. I don't care. It's too soon. Um, I don't really even do- I don't do the flu shot. I don't do- I only do what's mandatory. And if COVID becomes mandatory, that's gonna be a big problem because I don't trust a year of research on it" (Sage).

Latti also expressed that she felt eventually all people would need to take the vaccine for the pandemic to end, but emphasized people are in different stages of willingness to take the vaccine. She stated, "If you wanna get it, you get it. If you don't, you just wait a little. And, of course, everybody's gonna have to take it eventually because really this is not going anywhere."

\section{Theme Three: Reasons for planning to get vaccinated}

Subtheme 3a: Trusted colleagues and peers getting vaccinated. A slim minority of youth $(n=3,13 \%)$ were already convinced that vaccination was the right plan for them. This sense of readiness was solidified by seeing healthcare work colleagues and other peers get vaccinated, as Aaliyah expressed: "For me, I feel like a lot of people close to my circle have already gotten [vaccinated]."

Youth shared seeing some of their peers starting to get the vaccine and sharing on social media:

"I know a few people just on my social media that I knew, like, from high school, that I-that I knew. It wasn't just somebody I saw walking down the hallway. They all got the shots, and they seemed to - it didn't affect them" (Aaliyah).

Subtheme 3b: Protecting self and family. One of the reasons for planning on vaccination was related to both protecting oneself and one's family, particularly when working at a job with heightened potential exposure:

"I feel like for me right now getting it would be more protective for my children. If I'm gonna be coming in and out of the hospital, I don't wanna spread anything to them" (Aaliyah).

Celina similarly described:

If [the vaccine is] gonna prevent you from getting coronavirus, then - um, all my kids are young. My oldest is only five, and my youngest is one, so they're, like, all really young. If [the vaccine] stops us from being in, like, being in the hospital, getting really sick. One of my sons has a lung condition, so if that stops him from getting sick? Even just a little cold, um, messes with him so, so bad. Like, he, uh, a little cold, he will cough and turn blue from how much he's coughing.

Subtheme 3c: Hope for return to normalcy. Although some youth expressed wanting to get vaccinated, they noted that issues with access and availability may hinder their ability to do so. Youth spoke in several focus groups about challenges with getting an appointment. Despite the challenges, a sense of hope permeated the discussions when thinking about getting "back to normal." Some youth expressed excitement for when they would become eligible and have access to the vaccine:

"I would love to get it. [Laughter] I don't know. I, for me, I feel like, I kind of trust it because why would the 
government give all these frontline healthcare workers and all these frontline other workers like police officers, um, ambulance drivers, people like that, this vaccine if it wasn't, like, good. You know?" (Celina).

"I don't know, maybe if it becomes widely available, I would love to get it because it's gonna prevent against COVID. And we'll be able to resume our normal lives. I'd love to do that" (John).

\section{Discussion}

The first known study of COVID-19 vaccination attitudes among parenting foster youth and recent foster care alumni has implications for the U.S. vaccination plan, particularly with regard to vaccination of young adults from marginalized backgrounds. At present, all US states have widespread COVID-19 vaccination availability, yet some young adults, such as those in the present study, may not be ready to participate in vaccination efforts. In fact, a study by the Kaiser Family Foundation published in late March 2021 indicated that $15 \%$ of young people aged $18-29$ years would only get vaccinated if required to do so- the largest percentage responding this way of the many different groups surveyed (Lopes \& 2021, 2021). A subsequent study published in December 2021 indicated that individuals who were younger, had lower levels of education, and who identified as non-Hispanic Black, continued to be overrepresented among those who had not yet received COVID-19 vaccination (Monte, 2021).

Youth in the current study expressed varying degrees of intention to get vaccinated, and their hesitancy was primarily related to desiring additional information about vaccination outcomes, and mistrust in vaccine efficacy and development process. Whereas concerns regarding vaccination outcomes may be less prevalent today as compared to early 2021, general mistrust in COVID-19 vaccination persists, especially among younger, less educated adults (Monte, 2021). Moreover, while racial and ethnic inequality in vaccination rates has decreased dramatically from 2021, it continues to persist among non-Hispanic Black residents. As of late September 2021, 61\% of those fully vaccinated in the U.S. are White, which mirrors their population rate, whereas $10 \%$ of those fully vaccinated are non-Hispanic Black (compared to their population rate of $12.4 \%$ ) (CDC, 2021). Several groups have vaccination rates considerably exceeding their population rate, including people who are non-Hispanic Asian and non-Hispanic multi-racial (6.4\% of vaccinated adults vs. $3 \%$ of the population, and $4.2 \%$ vs. $2.3 \%$, respectively) (CDC, 2021). Those who have been vaccinated at rates similar to their population rate include Hispanic ( $16.7 \%$ of vaccinated compared to their population rate of 17.2\%), non-Hispanic Native Hawaiian and other Pacific Islander $(0.3 \%$ of vaccinated vs. $0.3 \%$ of the population), and non-Hispanic American Indian and Alaska Native adults ( $1 \%$ of vaccinated adults vs. $0.8 \%$ of the population).

Overall, while COVID-19 vaccination rates in all age groups have increased dramatically since early 2021, some young adults continue to exhibit hesitancy towards vaccination (Monte, 2021) and may not plan to get vaccinated in the future due to concerns about the safety and efficacy of the vaccine (Manchester, 2021). Addressing young adults' concerns about the efficacy evidence of the COVID-19 vaccines will involve science communication via additional channels, featuring voices with racial, gender, and age diversity. Youth, particularly those who have been in foster care and may have been mistreated through that system, need opportunities to raise their questions without judgment and to be involved in health communications regarding vaccination of their age group. As we have seen across the U.S., availability is a necessary but incomplete solution to address inequitable uptake of the vaccine across groups. Based on youths' perspectives, we offer several recommendations for intervention:

Provide opportunities to discuss vaccination-related concerns using trusted sources. Young adults need opportunities to discuss vaccination concerns openly and without judgment, and should receive vaccine-related information from sources that they consider trustworthy. This is particularly important for youth in foster care and recent foster care alumni, who may exhibit a high degree of mistrust in public systems. Addressing these youths' concerns about the efficacy of the COVID-19 vaccines and their potential risks and benefits will involve science communication via nontraditional channels, including social media and informal discussions with peers, featuring voices with racial, gender, and age diversity.

Facilitate convenient access to vaccination and address potential barriers. Youth in foster care, recent foster care alumni, and other marginalized young adults should be given a convenient access to COVID-19 vaccination. This should include walk-in appointments that do not require pre-registration, the ability to bring children to the appointment, or the availability of childcare onsite, and access to vaccination sites that do not require significant travel (e.g., mobile vaccination sites). Employers should also play a role in facilitating vaccination access for these youth, such as allowing paid time off from work to get vaccinated.

Address vaccine misinformation directly, but without stigmatization. Youth in foster care, recent foster care alumni, and other marginalized young adults, may be exposed to significant misinformation about COVID-19 vaccines. Addressing such misinformation is essential, but this should be done in a sensitive and non-stigmatizing manner, 
and by using sources that the youth trust. Prior research suggests that emphasizing the vaccines' high efficacy against hospitalization and death, and explaining that the new vaccination techniques have been in the works for many years, may constitute effective messaging for individuals who are uncertain about vaccination (Motta et al., 2021). For youth in foster care and recent foster care alumni, it is important to identify trusted individuals (many of whom may not be affiliated with the child welfare system) who can deliver such messaging successfully.

\section{Limitations}

The current study was conducted in the United States within a particular time period early in the rollout of the COVID19 vaccination program. Attitudes towards vaccination are changing as people see friends, family, colleagues, and other peers being vaccinated, thus, some concerns described by the study participants may be less prevalent today.The study relied upon a convenience sample of young parents currently in foster care or recently aged out of foster care recruited through social media and snowball sampling. These design characteristics should be taken into consideration when applying the findings to individuals outside of the study.

\section{Future Directions}

As we continue to study COVID-19 vaccination attitudes and uptake among foster youth and foster care alumni, it will be important to study which messages and channels are most effective for uplifting and addressing young people's questions and concerns. Through our research and direct practice, it is critical to center young people's right to selfdetermination in decisions about their health and well-being, conveying respect and an open, authentic stance towards answering questions and addressing the pandemic together.

Acknowledgements We gratefully acknowledge our participants for sharing their experiences so that other youth might benefit.

Funding This study was funded by the Annie E. Casey Foundation (Co-PI's Aparicio and Shpiegel, grant GA-2020-X6102). Views expressed are those of the authors.

\section{Declarations}

Conflict of interest The authors have no conflicts of interest to report.

Compliance with ethical standards The authors have no potential conflicts of interest to disclose. This study involved human participants and all procedures were approved by Montclair State University's In- stitutional Review Board.All participants provided informed consent to participation.

\section{References}

Abbasi, J. (2020). Younger Adults Caught in COVID-19 Crosshairs as Demographics Shift. JAMA, 324(21), 2141. https://doi. org/10.1001/jama.2020.21913

Bailey, Z. D., Feldman, J. M., \& Bassett, M. T. (2021). How Structural Racism Works-Racist Policies as a Root Cause of U.S. Racial Health Inequities. New England Journal of Medicine, 384(8), 768-773. https://doi.org/10.1056/NEJMms2025396

Birth-18 Years Immunization Schedule | CDC. https://www.cdc.gov/ vaccines/schedules/hcp/imz/child-adolescent.html

Boehmer, T. K., DeVies, J., Caruso, E., van Santen, K. L., Tang, S., Black, C. L. ... Gundlapalli, A. V. (2020). Changing Age Distribution of the COVID-19 Pandemic - United States, May-August 2020. MMWR. Morbidity and Mortality Weekly Report, 69(39), 1404-1409. https://doi.org/10.15585/mmwr.mm6939e1

Braun, P., \& Clarke, V. (2006). Using thematic analysis in psychology. Qualitative Research in Psychology, 3, 77-101

CDC. COVID Data Tracker. Centers for Disease Control and Prevention. https://covid.cdc.gov/covid-data-tracker

Combs, K. M., Begun, S., Rinehart, D. J., \& Taussig, H. (2018). Pregnancy and childbearing among young adults who experienced foster care. Child Maltreatment, 23(2), 166-174. https://doi. org/10.1177/1077559517733816

Connolly, J., Heifetz, M., \& Bohr, Y. (2012). Pregnancy and Motherhood Among Adolescent Girls in Child Protective Services: A Meta-Synthesis of Qualitative Research. Journal of Public Child Welfare, 6(5), 614-635. https://doi.org/10.1080/15548732.2012. 723970

Creswell, J. W., \& Poth, C. N. (2018). Qualitative Inquiry and Research Design (4th ed.). Sage Publications, Inc.

Dettlaff, A. J., \& Boyd, R. (2020). Racial Disproportionality and Disparities in the Child Welfare System: Why Do They Exist, and What Can Be Done to Address Them? The ANNALS of the American Academy of Political and Social Science, 692(1), 253-274. https://doi.org/10.1177/0002716220980329

Dworsky, A., Napolitano, L., \& Courtney, M. (2013). Homelessness During the Transition From Foster Care to Adulthood. American Journal of Public Health, 103(S2), S318-S323. https://doi. org/10.2105/AJPH.2013.301455

Fowler, P. J., Marcal, K. E., Zhang, J., Day, O., \& Landsverk, J. (2017). Homelessness and aging out of foster care: A national comparison of child welfare-involved adolescents. Children and Youth Services Review, 77, 27-33. https://doi.org/10.1016/j. childyouth.2017.03.017

Gilkey, M. B., Calo, W. A., Marciniak, M. W., \& Brewer, N. T. (2017). Parents who refuse or delay HPV vaccine: Differences in vaccination behavior, beliefs, and clinical communication preferences. Human Vaccines \& Immunotherapeutics, 13(3), 680-686. https:// doi.org/10.1080/21645515.2016.1247134

Khubchandani, J., Sharma, S., Price, J. H., Wiblishauser, M. J., Sharma, M., \& Webb, F. J. (2021). COVID-19 Vaccination Hesitancy in the United States: A Rapid National Assessment. Journal of Community Health, 46(2), 270-277. https://doi.org/10.1007/ s10900-020-00958-x

Lacombe-Duncan, A., Newman, P. A., \& Baiden, P. (2018). Human papillomavirus vaccine acceptability and decision-making among adolescent boys and parents: A meta-ethnography of qualitative studies. Vaccine, 36(19), 2545-2558. https://doi.org/10.1016/j. vaccine.2018.02.079 
Lopes, L. (2021). \& (2021, March 30). KFF COVID-19 Vaccine Monitor: March 2021. KFF. https://www.kff.org/coronavirus-covid-19/ poll-finding/kff-covid-19-vaccine-monitor-march-2021/

Manchester, J. (2021, March 1). 41\% say they are not willing to receive coronavirus vaccine [Text]. TheHill. https://thehill.com/ policy/healthcare/541044-41-percent-say-they-are-not-willingto-receive-coronavirus-vaccine

McQuillan, G., \& Unger, E. R. (2017). Prevalence of HPV in Adults Aged 18-69: United States, 2011-2014. 280, 8

Monte, L. (2021). Household Pulse Survey Shows Many Don't Trust COVID Vaccine, Worry About Side Effects. United States Census Bureau. https://www.census.gov/library/stories/2021/12/whoare-the-adults-not-vaccinated-against-covid.html

Motta, M., Sylvester, S., Callaghan, T., \& Lunz-Trujillo, K. (2021). Encouraging COVID-19 Vaccine Uptake Through Effective Health Communication. Frontiers in Political Science, 3, 630133. https://doi.org/10.3389/fpos.2021.630133

NEJM - Race and Medicine. (n.d.). New England Journal of Medicine. Retrieved March 2, from https://www.nejm.org/ race-and-medicine
Perri, M., Dosani, N., \& Hwang, S. W. (2020). COVID-19 and people experiencing homelessness: Challenges and mitigation strategies. Canadian Medical Association Journal, 192(26), E716-E719. https://doi.org/10.1503/cmaj.200834

Racism in medicine | The BMJ. (n.d.). Retrieved March 2, from https:// www.bmj.com/racism-in-medicine

Razai, M. S., Osama, T., McKechnie, D. G. J., \& Majeed, A. (2021). Covid-19 vaccine hesitancy among ethnic minority groups. BMJ, 372, n513. https://doi.org/10.1136/bmj.n513

Shpiegel, S., \& Cascardi, M. (2018). The impact of early childbirth on socioeconomic outcomes and risk indicators of females transitioning out of foster care. Children and Youth Services Review, 84, 1-8. https://doi.org/10.1016/j.childyouth.2017.11.001

Washington, H. (n.d.). Medical Apartheid: The Dark History of Medical Experimentation on Black Americans from Colonial Times to the Present. Doubleday

Xiao, X., \& Wong, R. M. (2020). Vaccine hesitancy and perceived behavioral control: A meta-analysis. Vaccine, 38(33), 5131-5138. https://doi.org/10.1016/j.vaccine.2020.04.076

Publisher's Note Springer Nature remains neutral with regard to jurisdictional claims in published maps and institutional affiliations. 